\title{
La aporofobia como desafío antropológico. De la lógica de la cooperación a la lógica del reconocimiento
}

\author{
Aporophobia as an anthropological challenge. From the logic of \\ cooperation to the logic of recognition
}

\author{
CÉSAR ORTEGA ESQUEMBRE*
}

\begin{abstract}
Resumen: el objetivo de este trabajo es poner en relación el núcleo crítico de la última obra de Adela Cortina, Aporofobia, que puede ser resumido como una protesta contra los límites del paradigma de la cooperación y la reciprocidad, con algunos elementos aparecidos en obras anteriores de la autora ${ }^{1}$. Para ello expondré primero algunos límites y virtualidades del paradigma de la reciprocidad. Tras bosquejar el núcleo de la obra Aporofobia, deteniéndome en los lugares en que este problema se hace más patente, terminaré rastreando algunos lugares anteriores en los que la autora anticipaba ya, desde una óptica diferente, esta misma crítica.

Palabras clave: Aporofobia, cooperación, reciprocidad, reconocimiento.
\end{abstract}

\begin{abstract}
: the aim of this paper is to connect the critical core of Adela Cortina's last work, Aporophobia, which can be summarized as a protest against the limitations of cooperation and reciprocity framework, with some elements appeared in Cortina's earlier works. To do this some of the limitations and advantages of the paradigm of reciprocity will be firstly described. Secondly the core of the work Aporophobia will be highlighted, specifically the places in which this problem become more evident. Some of the earlier works in which Cortina anticipated this same criticism through a different lens will be finally reviewed.
\end{abstract} Keywords: Aporophobia, cooperation, reciprocity, recognition.

\section{Introducción}

Hace ya tiempo que disciplinas como la antropología evolutiva, la teoría económica y la filosofía moral dejaron atrás esa decepcionante visión del ser humano que, muy genéricamente, puede ser apresada bajo la etiqueta de "homo oeconomicus". Las antiguas compren-

Recibido: 23/01/2018. Aceptado: 07/06/2018.

* Personal Investigador en Formación en la Facultad de Filosofía y Ciencias de la Educación de la Universidad de Valencia. Correo electrónico: cesar.ortega@uv.es Líneas de investigación: teoría crítica de la sociedad, ética del discurso, filosofía moral, política y social. Publicaciones recientes: “¿Naturalizar la idea de justicia? Una respuesta crítica desde la teoría moral de Jürgen Habermas”. Pensamiento, 72 (273), 2016, 827-848. "Habermas y Marcuse contra la ideología tecnocrática. Divergencias en la Teoría Crítica”. Daimon, 71, 2017, 47-62.

1 Este estudio se inserta en el Proyecto de Investigación Científica y Desarrollo Tecnológico FFI2016-76753C2-1-P, financiado por el Ministerio de Economía y Competitividad. Su elaboración ha sido asimismo posible gracias a la financiación del Programa de Formación del Profesorado Universitario dependiente del Ministerio de Educación, Cultura y Deporte (FPU2016). 
siones del ser humano como ente eminentemente maximizador de beneficios, dispuesto por así decir a cualquier cosa con tal de satisfacer sus impulsos autointeresados, dan paso, lo mismo en la moderna teoría de juegos que en las explicaciones naturalistas de la moral, a una versión desde luego más amable de la naturaleza humana, según la cual los sujetos se mueven de acuerdo con la lógica de la cooperación y la reciprocidad. Bajo esta antropología, que sin duda se compadece mejor con la gramática contractualista de nuestras sociedades democrático-liberales, las personas estarían dispuestas a satisfacer los intereses de otros sujetos con tal de que se les garantizase una recompensa futura.

Aunque, naturalmente, el nuevo marco logra resolver muchos de los problemas que afectaban a la antigua comprensión reductiva del ser humano, quizás hoy sólo defendible desde una trasnochada filosofía política de corte libertario, se enfrenta sin embargo a algunos nuevos desafíos, en los que merece la pena detener el ejercicio del concepto.

Justamente sobre uno de estos desafíos se construye el nuevo libro de Adela Cortina, Aporofobia. La obra persigue dar nombre a un fenómeno que, con su sola existencia, quiebra normativamente la pretensión de universalidad de esa lógica del intercambio infinito a que apela el concepto de "homo reciprocans". La aversión al pobre constituye un desafío moral, político y jurídico que de ninguna manera puede superarse recurriendo a la nueva antropología, precisamente porque el pobre es aquel que, por definición, no tiene nada que ofrecer en la lógica contractualista.

El objetivo de este trabajo es comparar este novedoso diagnóstico crítico social, que Cortina fundamenta en estudios procedentes de la antropología evolutiva y las ciencias sociales, con algunos elementos aparecidos en obras anteriores, en las que la autora recurría también a la crítica contra los límites del modelo de la reciprocidad. Para ello comenzaremos exponiendo en qué sentido el paradigma de la reciprocidad, si bien consigue superar la antigua y más grosera antropología economicista, se enfrenta sin embargo al problema decisivo de no poder justificar comportamientos que trascienden la lógica convencionalista de la cooperación autointeresada. Tras perfilar el núcleo de Aporofobia, deteniéndonos en los lugares en que este problema se hace patente y formulando la solución de Cortina en términos de un "reconocimiento cordial", rastrearemos en tercer lugar algunos momentos anteriores en los que la autora anticipaba ya desde una óptica diferente esta misma crítica. En último lugar plantearemos la pregunta acerca del estatuto teórico del diagnóstico de Cortina: ¿se trata de un diagnóstico crítico-anticipativo, en el sentido de ofrecer la anticipación de una situación social emancipada a cuya contraluz normativa se hace evidente la patología social? ¿O más bien de un diagnóstico crítico-reconstructivo, en el sentido de observar ya realizada en las relaciones intersubjetivas, aunque de deforme deficiente, esa situación social emancipada?

\section{Las limitaciones del paradigma de la reciprocidad}

Con el objetivo de superar uno de los grandes retos de la teoría de la evolución, a saber, el hecho de que las prácticas altruistas no se ejerzan tan sólo con familiares y miembros del grupo social -lo cual podía ser explicado por la llamada "selección por parentesco" (Hamilton, 1964) y la teoría darwinista de la "selección de grupos" (Darwin, 1980)-, sino también con personas ajenas al propio entorno, algunas modernas teorías naturalistas de la moralidad han recurrido a un nuevo paradigma antropológico que deja atrás el antiguo marco utilizado 
por la escuela clásica de economía. Frente a la modelización del comportamiento humano en términos de maximización racional de beneficios, este nuevo modelo explicativo reconoce la existencia de una capacidad intrínseca al ser humano, según la cual los sujetos tienden a mantener relaciones de reciprocidad y cooperación entre sí con el objetivo de procurarse mayores beneficios que los que alcanzarían siguiendo la lógica de la competencia.

Esta forma de reciprocidad no se agota en el comportamiento, típicamente preconvencional utilizando el lenguaje de Lawrence Kohlberg (1992), de un intercambio directo de favores -"reciprocidad directa" o "altruismo recíproco" (Trivers, 1971)-, sino que refiere también a lo que algunos autores han denominado "reciprocidad indirecta" (Alexander, 1987; Novak, 2005), donde la devolución del favor no se espera del sujeto al que a su vez se ha favorecido, sino de otros sujetos diferentes. Sobre la base de esta forma de comportamiento, que incentiva la aparición de acciones cooperativas, y recurriendo también a la importante noción de "reputación social", se ha pretendido explicar en términos evolutivos el desarrollo de la moralidad (Tomasello, 2013).

Como es natural, esta antropología resulta comparativamente más deseable tanto en términos descriptivos -la cooperación parece ajustarse mejor a las formas habituales de acción social que la pura rivalidad competitiva-, como especialmente en términos normativos -pues sustituye la antigua visión filosófico-política de la sociedad como conjunto de individuos atomizados que buscan maximizar sus beneficios por una comprensión basada en la idea de la cooperación entre sujetos que se saben mutuamente necesitados para lograr sus fines-. Pese a esta nada desdeñable ventaja, la nueva antropología deja ver sus deficiencias normativas tan pronto como se hace explícita la pregunta que acaso no puede dejar de venir a la conciencia tras la exposición anterior: ¿qué ocurre con los sujetos que no tienen nada que aportar en el juego del intercambio ilimitado?

Sobre la base de esta pregunta, Adela Cortina ha mostrado cómo el principio de la reciprocidad, efectivamente adecuado para apresar descriptivamente nuestras sociedades, tiene que tener la fatal consecuencia de una exclusión sistemática de determinados sectores de la población, y es justamente esta exclusión la que caracteriza a la aporofobia: «en la sociedad contractualista y cooperativa del intercambio se excluye al radicalmente extraño, al que no entra en el juego del intercambio, porque no parece que pueda ofrecer ningún beneficio como retorno» (Cortina, 2017: 80). Aunque bajo la lógica de la cooperación los sujetos no se conciben mutuamente como meros rivales a desalojar en la lucha por la existencia, sino más bien como compañeros de interacción que se necesitan mutuamente para desarrollar sus planes de acción, lo cierto es que permanece en ella ese irritante halo de instrumentalización, al que una comprensión postconvencional del ser humano no tiene más remedio que oponerse. Lo mismo en la antropología economicista que en la antropología de la reciprocidad, el otro no aparece como el kantiano fin en sí mismo cuya dignidad reclama respeto, sino sencillamente como un medio del que poder servirse a fin de conseguir objetivos en todo caso particulares.

\section{La aporofobia como desafío. De la reciprocidad al reconocimiento}

En su obra Aporofobia, Cortina parte del rechazo generado en amplios sectores poblacionales de los países europeos tras la acogida de refugiados para poner sobre la mesa el siguiente fenómeno: «es imposible no comparar la acogida entusiasta y hospitalaria con 
que se recibe a los extranjeros que vienen como turistas con el rechazo inmisericorde a la oleada de extranjeros pobres» (Cortina, 2017: 13). Este desconcertante hecho muestra hasta qué punto a la base de la reacción contra las políticas de acogida no hay un sentimiento de xenofobia, sino una patología social diferente y hasta el momento no diagnosticada. El libro se propone así dar nombre a esta patología social, con el objetivo de contribuir a su posible superación.

Al igual que otras patologías sociales como la xenofobia o la homofobia, lo peculiar de las actitudes aporófobas es que no van dirigidas contra personas concretas a las que se les imputa un determinado rasgo negativo, sino más bien contra miembros en abstracto de un determinado colectivo considerado despreciable. Tras realizar un interesante análisis sobre los delitos de odio y los discursos del odio, Cortina se esfuerza por rastrear las bases biológicas de las actitudes aporófobas y xenófobas.

Cortina parte de algunas investigaciones neurobiológicas para constatar la existencia de ciertas tendencias innatas al ser humano, tanto de tipo negativo -el autointerés o la xenofobia- como positivo - la simpatía selectiva o la empatía-. El autointerés nos lleva a rechazar todo aquello que nos perturba o que parece no poder aportar nada positivo, y es precisamente aquí donde se encuentra la raíz biológica de la aporofobia: «las emociones que conducen a prejuicios raciales y culturales tienen su base en emociones sociales que, desde el punto de vista evolutivo, servían para detectar las diferencias que podían señalar un riesgo o un peligro, e incitar a retirarse o a agredir» (Cortina, 2017: 73). Tal y como muestra Emilio Martínez, las actitudes aporófobas son adquiridas también culturalmente como consecuencia de procesos de socialización defectuosos, por ejemplo como consecuencia de «relatos alarmistas y sensacionalistas que relacionan a las personas de escasos recursos con la delincuencia y con una supuesta amenaza a la estabilidad del sistema socioeconómico» (Martínez, 2002: 17). Con esto parece perpetuarse lo que Martínez denomina "el círculo vicioso de la aporofobia".

Sea como fuere, la existencia de esa base biológica no significa, sin embargo, que estemos determinados a presentar patologías sociales. Al margen de que, tras el esperanzador descubrimiento de la plasticidad cerebral, sabemos que nos es dable modular culturalmente el cerebro para configurar en sentidos diferentes las predisposiciones biológicas, existen en la propia base biológica del ser humano «otras tendencias evaluativas universales que podemos reforzar para reducir e incluso eliminar esas fobias, como es el caso de la tendencia a cuidar de otros». Como vimos más arriba, no sólo la tendencia al cuidado de los familiares y cercanos, sino también la preocupación por sujetos ajenos al propio grupo, podía ser explicada en términos de interés adaptativo.

Aunque esta visión naturalista, que abona las versiones antropológicas de la cooperación y la reciprocidad, trasciende la comprensión atomística de la sociedad y el modelo economicista del ser humano, es claro que sigue teniendo un carácter convencional. La aporofobia actúa como quiebra normativa de la antropología de la reciprocidad, precisamente porque existe un colectivo que no tiene ninguna posibilidad de participar en el juego del intercambio. Aunque son muchos los que en la actualidad reivindican una solución para el desafío de las tendencias biológicas negativas en términos de "biomejora moral", Cortina cree localizar el "antídoto" en un lugar diferente. Siguiendo el programa filosófico moral iniciado a comienzos de los años noventa (Cortina, 1990) y sistematizado dos décadas después en forma de una ética de 
la razón cordial (Cortina, 2007; 2010), Cortina parte de dos principios éticos básicos inscritos en la propia gramática de reconocimiento recíproco que une entre sí, de forma previa a todo pacto, a los seres humanos: el respeto por la igual dignidad de toda persona y la compasión ante el dolor de los sujetos vulnerables. Frente a la lógica de la cooperación, basada todavía en una autocomprensión instrumentalista del ser humano, en la lógica del reconocimiento los compañeros de interacción se conciben mutuamente como fines en sí mismos cuya dignidad reclama respeto, incluso cuando no es previsible que esta actitud reporte al agente beneficio alguno. La consolidación de estos principios en la vida cotidiana exige a juicio de la autora la participación de la educación formal e informal y la creación de instituciones y organizaciones encaminadas a reforzar el reconocimiento de los sujetos desposeídos.

Cortina consigue demostrar la urgencia de trascender no sólo el paradigma del egoísmo y la búsqueda del máximo beneficio, sino también el de la cooperación y la reciprocidad. Sólo tras este segundo paso se podría transitar hacia el modelo de un reconocimiento recíproco «que rompe barreras y se extiende universalmente» (Cortina, 2017: 81), es decir, hacia la forma de organización social, normativamente superior, de una hospitalidad solidaria verdaderamente universal.

\section{Solidaridad, no cooperación}

Aunque sólo tras sus estudios sobre neuroética (Cortina, 2011) Cortina pudo formular la crítica al paradigma de la cooperación en conceptos tomados de la antropología evolutiva, lo cierto es que esta crítica aparece ya de forma clara en trabajos anteriores, esta vez sobre el telón de fondo de los debates filosófico políticos entre liberalismo y socialismo.

El primer lugar al que debemos acudir para localizar una formulación explícita es la obra de 1990 Ética sin moral, donde Cortina tomaba partido en favor de una ética de la Modernidad crítica que, inscrita en las filas deontológicas de la ética discursiva, trataba sin embargo de superar sus limitaciones procedimentalistas articulando el momento de la corrección normativa con elementos provenientes de tradiciones filosóficas anteriores, tales como los móviles morales, los sentimientos y las virtudes. Tras ofrecer un soberbio recorrido por algunas de las corrientes éticas más significativas y articular las aristas del ámbito práctico -moral, derecho y política- desde el punto de vista de una ética discursiva revisada, Cortina desarrolla su propia propuesta concreta. Para ello parte de una antropología mínima que entiende al ser humano, en la línea de la reformulación intersubjetiva del kantismo (Apel, 1991; Habermas, 2008), como "hablante competente" para pronunciarse en discursos destinados a la justificación de normas que le afectan. Bajo el trasfondo de esta antropología, Cortina se esfuerza por superar las versiones pervertidas de los paradigmas liberal y socialista, el individualismo y el colectivismo respectivamente, en un nuevo modelo que reivindica al mismo tiempo el valor de la autonomía y el de la solidaridad. En la línea de autores liberales como Rawls o Dworkin, la autora hace valer los méritos de un liberalismo revisado que, retornando desde el "individualismo posesivo" (Macpherson, 2005) hasta la noción kantiana de "autonomía personal", incorpora los valores de la solidaridad y la cooperación. Por su parte, en la línea de la ética política socialista de autores como Habermas y Apel, Cortina reivindica una recuperación de la solidaridad que no menoscabe el valor absoluto del individuo. 
Pero, aunque el socialismo tiene que incidir en el valor de la autonomía individual, ello no significa que su valor sagrado, la solidaridad, deba quedar reducido por vía liberal a la noción de "cooperación": «si el egoísmo supone autocentramiento y la afirmación del individuo como axiológicamente anterior a la comunidad, de modo que cada individuo valore la vida comunitaria y a los demás hombres según el beneficio que le reporten, el hombre solidario se sabe inscrito ya en una comunidad humana, con la que ya comparte intereses, y además valora como en sí valioso a cada uno de sus componentes» (Cortina, 1990: 288). Siguiendo la tradición del reconocimiento recíproco en que se inscriben autores como Hegel (2017), Mead (1999), Honneth (1997) o Taylor (2009), Cortina defiende que únicamente a través de la inserción en una comunidad de comunicación los sujetos pueden configurar su propia identidad.

Este intento de superar dialécticamente la atávica tensión entre liberalismo y socialismo es retomado en La moral del camaleón, donde puede localizarse una detallada formulación de la crítica que nos interesa. Cortina recurre a las raíces morales de las ideologías liberal y socialista para superar no sólo la perversión colectivista del socialismo marxista, sino también algunas versiones socialistas de la época -el llamado "Programa 2000"- que a su juicio terminaban por perder las señas de identidad del socialismo. Este nuevo "individualismo de izquierdas", basado en una comprensión reductiva de la solidaridad en términos de "cooperación para el beneficio mutuo", acababa por renunciar al núcleo universalista de la moral socialista. Frente a las tesis liberales sobre el cálculo del beneficio como base de la moral, heredadas más tarde por el nuevo socialismo, se alzan a juicio de Cortina «el descubrimiento de la propia pertenencia a una comunidad y el de que hay seres -los hombres- en sí, y no sólo para mí, valiosos» (Cortina, 1991: 49).

Cortina parece decantarse por la vía de una interpretación filosófica de la autonomía de corte socialista, que no se limita a superar la antigua lógica economicista de la rivalidad en favor del paradigma de la cooperación racional, sino que toma consciencia a su vez de las limitaciones de este modelo para los casos de los sujetos radicalmente desposeídos: «la solidaridad habrá de expresarse mediante la cooperación, siempre que ello sea posible, pero el trasfondo seguirá siendo el reconocimiento del valor propio y el ajeno, aun en los casos en que alguien no pudiera cooperar» (Cortina, 1991: 50). Esta tradición socialista, que bebe lo mismo de Kant que de las tesis sobre la individuación por socialización de Hegel y Mead, reivindica el valor, por así decir constitutivo para la propia identidad, de los procesos de reconocimiento: «no se trata de hacer de la cooperación una actitud aconsejable a los individuos, sino de mostrar que la solidaridad es el elemento vital de los hombres» (Cortina, 1991: 52). Apoyada en las valiosas aportaciones de la ética de la liberación - «el principio de la ética no puede ser sino el rostro del otro»-, la autora anticipaba ya en esta temprana obra el diagnóstico crítico-social que sólo en Aporofobia quedaría sistematizado, destacando la figura del pobre como la ruptura total de la gramática social: «el pobre es precisamente, por su esencia, ese interlocutor potencial, que nunca lo será real» (Cortina, 1991: 127).

También en Ética de la razón cordial, donde Cortina ofrece un recorrido por la historia de la filosofía moral-política capaz de detectar posibles respuestas a la pregunta por las fuentes de la obligación moral, podemos localizar la crítica que nos interesa. La primera de estas respuestas, que representarían Maquiavelo y Hobbes, encarnaría a juicio de Cortina esa antropología pre-cooperativa que revela en su forma más radical las comprensiones 
instrumentalizadoras del ser humano. Maquiavelo basaba sus recomendaciones políticas en un paradigma teórico -bautizado posteriormente como "teoría del interés más fuerte" (Hirschman, 1978) - que reducía la noción de "racionalidad" a la idea de una supeditación de las pasiones al interés egoísta más poderoso.

Como sabemos, esta versión temprana del individualismo egoísta, que sería paradigmáticamente recogida en la explicación hobbesiana de la obligación política, no puede apresar en forma completa una realidad social que evidentemente no siempre se fundamenta sobre el cálculo interesado. Siguiendo su recorrido, Cortina encuentra una posible solución a las deficiencias del primer modelo en los representantes de la teoría del sentimiento (Hume, Smith y Mill), donde los sentimientos sociales positivos y negativos constituirían las fuentes de la obligación moral. Parece que justamente en esta tradición tiene sentido insertar la llamada "antropología de la reciprocidad". Reformulando su crítica en términos de oposición entre moral convencional y postconvencional, Cortina hace ver cómo estas teorías resultan insuficientes para dar cuenta de las fuentes de una obligación moral que aspira a ser universalista, pues de ellas «no surge una moral de personas capaces de criticar y tomar posiciones autónomas, sino esas costumbres que generan una moral atrozmente conservadora, temerosa de cualquier posición que el grupo social pueda tener por inadecuada» (Cortina, 2007: 94).

Las dos siguientes tradiciones a que apela Cortina en su reconstrucción, Kant y la ética discursiva, sirven naturalmente para corregir este déficit particularista. Pero como ya sabemos Cortina no se conforma con el último de los paradigmas de la ética neokantiana -la reformulación procedimentalista de Apel y Habermas-, sino que trata de dar un paso más en la dirección de una ética de la razón cordial que incorpora las aportaciones de la ética de los valores y la ética clásica. Tratando de superar la dimensión lógico-formal a que la ética discursiva había limitado la racionalidad, y sobre el trasfondo de lo que Jesús Conill ha llamado "razón experiencial" (Conill, 2006), Cortina muestra cómo la propia competencia comunicativa presupone como condición de posibilidad que los interlocutores se reconozcan mutuamente en un sentido más amplio, lo cual a su vez sólo es posible si se presupone en los sujetos tres capacidades adicionales: el sentimiento de emociones, la estimación de valores y la adquisición de virtudes.

El reconocimiento cordial, basado a la vez en la comprensión de la igual dignidad de todo sujeto, en tanto sujeto que puede actuar como interlocutor válido, y en el sentimiento de compasión inspirado por una vulnerabilidad constitutiva del ser humano, funciona entonces como la fuente de la obligación moral. Sólo partiendo de este concepto ampliado de reconocimiento recíproco parece poder sustituirse no sólo el asilvestrado paradigma del individualismo posesivo, sino también una igualmente decepcionante antropología de la reciprocidad que, acaso de forma inadvertida, termina por arrebatar a uno de los principios ilustrados fundamentales -la solidaridad- el rasgo que de verdad lo hace fundamental: su carácter universalista.

\section{4. ¿Crítica anticipativa o crítica reconstructiva?}

Aunque es muy evidente la fuerza normativa del diagnóstico de Cortina, en la reconstrucción que nosotros hemos ofrecido parece pervivir una cuestión no del todo aclarada. Los enunciados en términos de "diagnóstico de la época", que con la noción de "aporofobia" 
quieren apresar una patología social encarnada en ese trato diferenciado que Occidente muestra hacia los extranjeros en función de sus posesiones materiales, parecen entrar en cierta tensión con los enunciados en términos de fundamentación filosófica de lo moral, con los que Cortina localiza dos principios normativos inscritos en la propia gramática de reconocimiento que une entre sí, ya de forma inmediata, a todos los seres humanos: el principio del respeto por la igual dignidad y el principio de la compasión ante el dolor de los sujetos vulnerables. Esta tensión únicamente aparece en la medida en que no se explicite suficientemente en qué momento se está operando con enunciados descriptivos -cómo funciona de hecho el mundo social-, y en qué momento se está operando con enunciados normativos -cómo debería funcionar, sobre el trasfondo de un determinado criterio normativo-. Damos por supuesto que el diagnóstico de Cortina no posee un carácter meramente sociológico, sino más bien filosófico-social ${ }^{1}$; es decir, que sus pretensiones no son tan sólo las de exponer el funcionamiento efectivo del mundo social, sino las de exponer este funcionamiento sobre un trasfondo normativo más amplio que pueda hacer emerger sus rasgos patológicos. Si esto es así, entonces surge una interesante pregunta, con cuyo breve comentario quisiéramos finalizar: ¿representa el diagnóstico crítico-social planteado una crítica anticipativa o una crítica reconstructiva?

Entendemos por "crítica anticipativa" aquella en la cual la situación social es criticada sobre el trasfondo normativo de una sociedad anticipada contrafácticamente. Sobre la idea de una sociedad verdaderamente emancipada, que en el modelo de Cortina representaría aquella situación en que se han visto satisfechas las relaciones de reconocimiento en sentido amplio, los contornos de la injusticia se hacen evidentes, precisamente como formas violentadas de esa situación. Por su parte, entendemos por "crítica reconstructiva" aquella que cree encontrar ya operantes, en la propia estructura social que quiere criticar, las exigencias normativas de la crítica, por mucho que estas exigencias aparezcan tan sólo muy difuminadamente. Como puede verse, en ambos casos se trata de un diagnóstico crítico, en el sentido de que presenta un carácter no solamente descriptivo, sino también normativo. Ambas formas de crítica social han de ir por tanto conectadas con una praxis reparadora que en último término cumple una función idéntica: la de clausurar la distancia existente entre facticidad e idealidad, por mucho que en la crítica reconstructiva esta idealidad pueda encontrarse de forma inmanente.

Aunque esta cuestión, que acaso está inscrita en los genes de la filosofía social desde el temprano intento hegeliano de hallar la idea de "libertad" realizada en las instituciones de la Modernidad (Hegel, 2010), resulta sumamente controvertida, quisiéramos finalizar tomando partido por una de las dos opciones. Siguiendo acaso el programa transcendental-reconstructivo utilizado también por el Habermas de Teoría de la acción comunicativa (Habermas, 2010) y el Apel de La transforamción de la filosofía (Apel, 1985), ese programa que creía poder descubrir en las propias estructuras de la acción comunicativa cotidiana una base de

1 Aquí se utiliza la noción "sociológico" no en el sentido que damos al término "sociología" cuando nos referimos a los programas de Durkheim o Weber, sino en el sentido que le damos cuando nos referimos a esas decepcionantes versiones actuales vacías de sustancia normativa, que son el resultado de la colonización positivista. Por "filosofía social" entiendo a su vez la línea de pensamiento que nace con la crítica a la civilización de Rousseau, continúa a través de Hegel hasta Marx, y conecta vía Lukács con la Escuela de Frankfurt. Para este segundo recorrido véase Honneth, 2011. 
validez universal, Cortina opera con dos principios normativos fundamentales -el respeto por la igual dignidad y la compasión ante la vulnerabilidad del ser humano- que desde luego no son idealistamente construidos, sino que pueden ser derivados de una noción de reconocimiento que está ya operando en las relaciones interpersonales, en la medida en que los individuos constituyen su identidad en procesos de socialización. Que estos principios normativos, reconstruibles de forma inmanente en las propias estructuras de la interacción social, son hoy violentados a través de esa espantosa patología que Cortina denomina "aporofobia" es algo muy evidente. Por eso el diagnóstico social no se conforma con esa particular «declaración de paz con el mundo inhumano», como decía Horkheimer para criticar el conformismo inscrito en el idealismo hegeliano (Horkheimer, 2008: 237), sino que trata de ofrecer instrumentos destinados a reforzar esa forma ampliada de reconocimiento, hoy en peligro.

\section{Bibliografía}

Alexander, R. (1987). The biology of moral systems, Hawthorne: Aldine de Gruyter Apel, K. O. (1985). La transformación de la filosofía, Madrid: Taurus, 2 vols.

Apel, K. O. (1991). "La ética del discurso como ética de la responsabilidad. Una transformación postmetafísica de la ética de Kant", en: Apel, K. O.: Teoría de la verdad y ética del discurso, Barcelona: Paidos, pp. 147-184

Conill, J. (2006). Ética hermenéutica: crítica desde la facticidad, Madrid: Tecnos

Cortina, A. (1990). Ética sin moral, Madrid: Tecnos

Cortina, A. (1991). La moral del camaleón: ética para nuestro fin de siglo, Madrid: EspasaCalpe

Cortina, A. (2007). Ética de la razón cordial, Oviedo: Nobel

Cortina, A. (2010). Justicia cordial, Madrid: Trotta

Cortina, A. (2011). Neuroética y neuropolítica: sugerencias para la educación moral, Madrid: Tecnos

Cortina, A. (2017). Aporofobia. El rechazo al pobre: un desafío para la democracia, Barcelona: Paidós

Darwin, Ch. (1980). El origen del hombre y la selección en relación al sexo. Madrid: Edaf

Habermas, J. (2008). "Ética del discurso. Notas para un programa sobre su fundamentación", en: Habermas, J.: Conciencia moral y acción comunicativa. Madrid: Trotta, pp. 54-119

Habermas, J. (2010). Teoría de la acción comunicativa. Madrid: Trotta

Hamilton, W. D. (1964). "The genetical evolution of social behaviour", Journal of theoretical biology, $\mathrm{n}^{\mathrm{o}} 7$, pp. 1-16

Hegel, G. W. F. (2010). Líneas fundamentales de la filosofía del derecho. Madrid: Gredos

Hegel, G. W. F. (2017). Fenomenología del espíritu. México: Fondo de Cultura Económica Hirschman, A. O. (1978). Las pasiones y los intereses: argumentos políticos en favor del capitalismo antes de su triunfo, México: Fondo de Cultura Económica

Honneth, A. (1997). La lucha por el reconocimiento, Barcelona: Crítica

Honneth, A. (2011). "Patologías de lo social: tradición y actualidad de la filosofía social", en: Honneth, A. La sociedad del desprecio. Madrid: Trotta

Horkheimer, M. (2008). "Teoría tradicional y teoría crítica”, en: Horkheimer, M. Teoría Crítica. Buenos Aires: Amorrortu 
Kohlberg, L. (1992). Psicología del desarrollo moral, Bilbao: Desclée de Brouwer

Macpherson, C. B. (2005). La teoría política del individualismo posesivo: de Hobbes a Locke, Madrid: Trotta

Martínez Navarro, E. (2002). “Aporofobia”, en Conill, J. (coord.). Glosario para una sociedad intercultural. Valencia: Bancaja

Mead, G. H. (1999). Espíritu, persona y sociedad. Barcelona: Paidós

Nowak, M. A. y Sigmund, K. (2005). "Evolution of indirect reciprocity", Nature, no 437, pp. 1291-1298

Taylor, Ch. (2009). "La política del reconocimiento", en: Gutmann, A. (ed.). El multiculturalismo y la "política del reconocimiento". México: Fondo de Cultura Económica

Trivers, R. L. (1971). "The evolution of reciprocal altruism", The Quartely Review of Biology, $\mathrm{n}^{\circ} 46$, pp. 35-57

Tomasello, M. y Vaish, A. (2013). "Origins of Human Cooperation and Morality", Annual Review of Psychology, $\mathrm{n}^{\circ}$ 64, pp. 231-255 